\title{
Article \\ Correlations for Total Entropy Generation and Bejan Number for Free Convective Heat Transfer of an Eco-Friendly Nanofluid in a Rectangular Enclosure under Uniform Magnetic Field
}

\author{
Yacine Khetib ${ }^{1,2}{ }^{(0}$, Hala M. Abo-Dief ${ }^{3}$, Abdullah K. Alanazi ${ }^{3}{ }^{(}$, Goshtasp Cheraghian ${ }^{4, *}{ }^{\infty}$, \\ S. Mohammad Sajadi ${ }^{5,6}$ and Mohsen Sharifpur ${ }^{7,8, * \text { (D) }}$ \\ 1 Mechanical Engineering Department, Faculty of Engineering, King Abdulaziz University, \\ Jeddah 80204, Saudi Arabia; ykhetib@yahoo.com \\ 2 Center Excellence of Renewable Energy and Power, King Abdulaziz University, Jeddah 80204, Saudi Arabia \\ 3 Department of Chemistry, College of Science, Taif University, Taif 21944, Saudi Arabia; \\ h.abodeif@tu.edu.sa (H.M.A.-D.); aalanaz4@tu.edu.sa (A.K.A.) \\ 4 Independent Researcher, 38106 Braunschweig, Germany \\ 5 Department of Nutrition, Cihan University-Erbil, Erbil 44001, Iraq; smohammad.sajadi@gmail.com \\ 6 Department of Phytochemistry, SRC, Soran University, Soran 44008, Iraq \\ 7 Department of Mechanical and Aeronautical Engineering, University of Pretoria, Pretoria 0002, South Africa \\ 8 Department of Medical Research, China Medical University Hospital, China Medical University, \\ Taichung 404, Taiwan \\ * Correspondence: goshtasbc@gmail.com (G.C.); mohsen.sharifpur@up.ac.za (M.S.)
}

Citation: Khetib, Y.; Abo-Dief, H.M.; Alanazi, A.K.; Cheraghian, G.; Sajadi, S.M.; Sharifpur, M. Correlations for Total Entropy Generation and Bejan Number for Free Convective Heat Transfer of an Eco-Friendly Nanofluid in a Rectangular Enclosure under Uniform Magnetic Field. Processes 2021, 9, 1930. https://doi.org/ $10.3390 /$ pr9111930

Academic Editor: Hussein A. Mohammed

Received: 31 August 2021 Accepted: 15 October 2021 Published: 28 October 2021

Publisher's Note: MDPI stays neutral with regard to jurisdictional claims in published maps and institutional affiliations.

Copyright: (c) 2021 by the authors. Licensee MDPI, Basel, Switzerland. This article is an open access article distributed under the terms and conditions of the Creative Commons Attribution (CC BY) license (https:/ / creativecommons.org/licenses/by/ $4.0 /)$.
Abstract: In this paper, focusing on the study of entropy generation (EGN), the convection flow of an eco-friendly nanofluid (N-F) in a rectangular enclosure is studied numerically. The nanoparticles (N-Ps) used are silver N-P, which are obtained in an eco-friendly manner from natural materials. By suspending these N-Ps in an equal mixture of water and ethylene glycol (E-G), the N-F has been prepared. There are two constant-temperature triangular obstacles with height $\mathrm{w}$ and base $\mathrm{H}$ that are placed on the hot wall. There is a magnetic field (M-F) in the $\mathrm{x}$-direction. To simulate the N-F flow, eco-friendly N-P relations are used, and the equations are solved using the volume control method and the SIMPLE algorithm. The variables include Rayleigh number (Ra), Hartmann number $(\mathrm{Ha}), \mathrm{H}, \mathrm{W}$, and the volume fraction of silver N-Ps. The effect of these parameters is evaluated on the EGN and Bejan number (Be). Finally, a correlation is expressed for the EGN for a range of variables. The most important results of this paper demonstrate that the addition of silver eco-friendly N-Ps intensifies the EGN so that the addition of $3 \%$ of N-Ps enhances the EGN by $3.8 \%$. An increment in the obstacle length reduces the Be barrier while increasing the $\mathrm{Ha}$, which enhances the Be when the convection is strong. Increasing the height of the obstacle intensifies entropy generation.

Keywords: triangular blades; natural convection; entropy generation; magnetic field; eco-friendly N-F

\section{Introduction}

In recent years, researchers have paid more attention to nanotechnology. Nanotechnology has applications in many industries, including medicine, aerospace, military, construction, food, heat transfer, renewable energy, etc. [1-5]. One of the applications of nanoparticles (N-Ps) in manufacturing is the preparation of nanofluids (N-Fs). N-Fs are widely used in heat transfer industries [6-10]. One of the important applications of nanofluids is their use in closed enclosures, which are used to enhance the improvement of thermal and refrigeration equipment [11-15]. Ghasemi and Aminossadati [16] investigated the effect of N-Fs in a square enclosure. They changed the percentage of N-Ps in the base fluid and found that a higher volume percentage leads to more heat transfer in the enclosure. Additionally, a rise in the Rayleigh number ( $\mathrm{Ra}$ ) leads to an increase in the vortices' velocity, suggesting an increase in heat transfer. Among the various N-Ps, some researchers have 
used eco-friendly N-Ps in their research. These N-Ps are made from natural materials and are environmentally friendly. Various materials have been utilized as N-Ps in investigations in the realm of N-Fs. Silver N-Ps have been increasingly popular in recent years because of their unique characteristics and many uses, which include medical equipment, heating systems, and apparel. The reduction of silver ions in solution or at high temperatures in gaseous settings is the general approach for producing silver N-Ps [17]. However, some researchers have proposed a new method for preparing these N-Ps from tea leaves. Mashayekhi et al. [18] studied the effect of using eco-friendly N-F on heat transfer rate. Their results demonstrated that using this N-F instead of base fluid enhances the rate of heat transfer. In another study, Essa et al. [19] assessed the effect of using eco-friendly coffee-based colloid on solar steel was studied. They mentioned the advantages of using this N-F as organic and the low cost of preparation. In another study, Kosinska et al. [20] investigated the effect of using coffee colloids eco-friendly N-Fs in a direct solar absorption collector. They used this N-F to reduce preparation costs and preserve the environment along with the desirable properties of this N-F. Other researchers have also used gold ecofriendly N-Ps in their studies [21]. The magnetic field (M-F) can apply a force to different materials called the Lorentz force. This force is very important in N-F flows, especially in the natural flow, and can fundamentally change the flow. One of the fascinating issues for researchers is the use of M-F in enclosures to investigate its influence and Hartmann number (Ha) changes on the natural flow field [22-25]. The influence of the M-F on various enclosure geometries was investigated by several researchers [26-28]. The impact of Ra and Ha on heat transfer rate, flow field, and temperature in an enclosure was investigated by Ghasemi and Aminossadati [29]. They found that an enhancement in the Ha weakens the flow field and also reduces the Nusselt number $(\mathrm{Nu})$. The use of $\mathrm{N}$-Fs can also enhance the $\mathrm{Nu}$.

The increasing need for energy on the one hand, and the increment in environmental pollution on the other hand, have prompted researchers to improve the efficiency of various devices as much as possible [30-34]. One of the solutions to enhance the efficiency is the evaluation of entropy generation (EGN) and the rate of irreversibility created in these devices. The researchers determined EGN in heat transfer devices to estimate their efficiency [35-38]. The study of EGN in enclosures has also been one of the interesting topics for researchers in recent years [39-43]. Aghakhani et al. [44] evaluated the EGN of a N-F in a closed enclosure under a M-F. Their findings indicated that increasing the enclosure's convection intensity increases the rate of EGN and heat transmission at the same time. Additionally, an increase in Ra lowers the quantity of Bejan number (Be).

The use of N-Ps in different industries has been growing in recent years, and also, the researches have been increased in the field of different N-Ps [45]. One of the problems with using N-Ps is their environmental concerns. One of the best ways to prevent environmental damage by using industrial N-Ps is to use N-Ps synthesized from natural materials. One of these N-Ps is silver N-Ps that can be produced using an industrial method from tea leaves. Due to this issue, it was decided to use an eco-friendly N-F in this study, which contains silver N-Ps obtained from natural materials dispersed in a mixture of water and ethylene glycol (E-G). In addition, considering the need to enhance the use of various devices in this article, the focus is on EGN. Therefore, in this paper, the impact of the natural flow of an eco-friendly N-F in an enclosure with two triangular blades is evaluated on EGN. The effect of the M-F on N-F flow is examined. Finally, by changing the Ra and Ha as well as the dimensions of the triangular blades, the EGN and the Be are investigated, and a correlation for EGN is provided. In summary, the use of eco-friendly N-Fs in the mentioned geometry is considered as the novelty of the present work.

\section{Problem Description}

The two-dimensional enclosure consists of a rectangular enclosure, with dimensions as shown in Figure A1. The enclosure has two walls of high temperature and low temperature and two insulated walls. Two triangular blades are mounted on the bottom wall. The 
distance between the sides of the blades is equal. The enclosure is saturated with ecofriendly silver N-Ps dispersed in 50:50 water and E-G. It is noteworthy that the N-Ps used are eco-friendly and synthesized from the environment. The enclosure is under a M-F in the direction as shown in Figure A1.

$3 \mathrm{~L}$

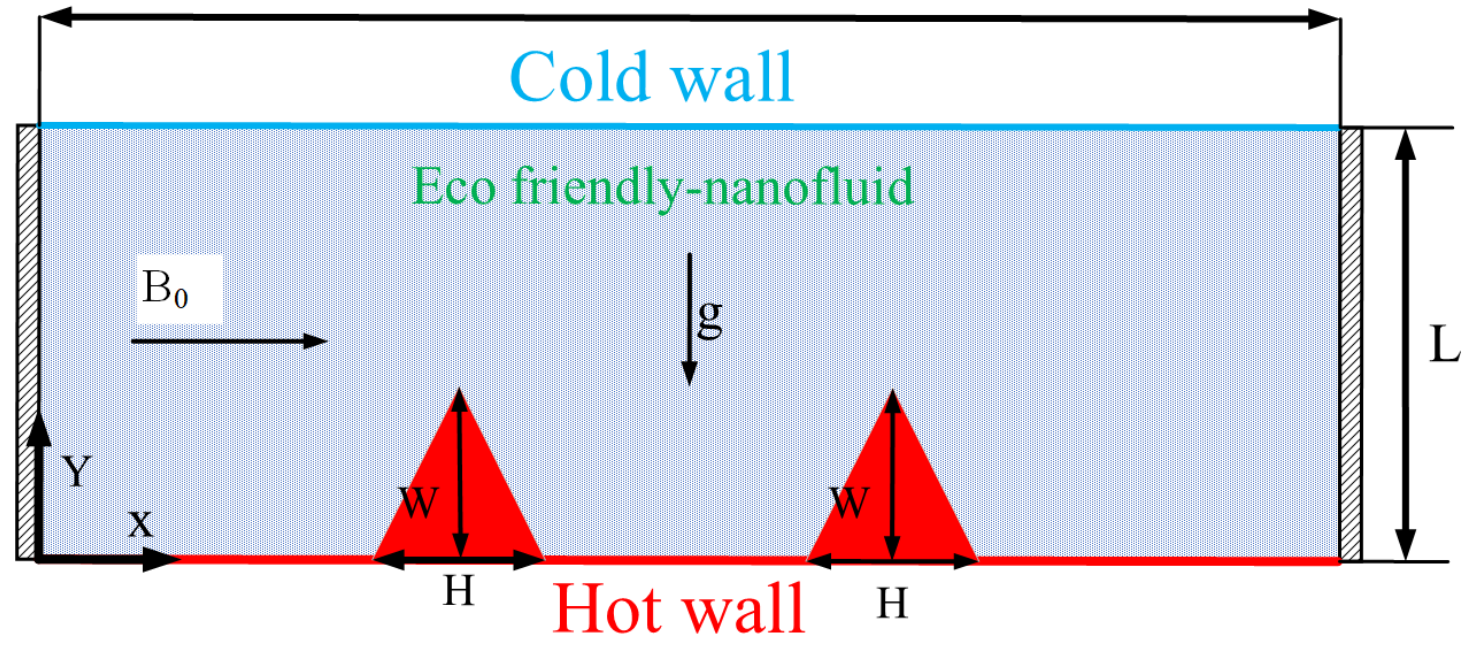

Figure A1. A schematic of the enclosure.

\subsection{Governing Equations and Boundary Condition}

The non-dimensional equations for the N-F flow, including the continuity, the momentum, and the energy equations, for steady laminar flow and incompressible Newtonian $\mathrm{N}-\mathrm{F}$, are as follows. Additionally, the effects of viscosity loss, radiative heat transfer, and volumetric forces except the gravitational force are neglected [40]:

$$
\begin{gathered}
U_{X}+V_{Y}=0, \\
U U_{X}+V U_{Y}=-\mathrm{P}_{X}+\frac{\mu_{\mathrm{nf}}}{\rho_{\mathrm{nf}} \alpha_{\mathrm{f}}}\left(\mathrm{U}_{X X}+\mathrm{U}_{Y Y}\right), \\
U V_{X}+V V_{Y}=-\mathrm{P}_{Y}+\frac{\mu_{\mathrm{nf}}}{\rho_{\mathrm{nf}} \alpha_{\mathrm{f}}}\left(\mathrm{V}_{X X}+\mathrm{V}_{Y Y}\right)+\frac{\beta_{\mathrm{nf}}}{\beta_{\mathrm{f}}} \operatorname{RaPr} \theta+\frac{\rho_{\mathrm{f}}}{\rho_{\mathrm{nf}}} \frac{\sigma_{\mathrm{nf}}}{\sigma_{\mathrm{f}}} \operatorname{PrHa}^{2} V, \\
\mathrm{U} \theta_{X}+\mathrm{V} \theta_{X}=\frac{\alpha_{\mathrm{nf}}}{\alpha_{\mathrm{f}}}\left(\theta_{X X}+\theta_{Y Y}\right),
\end{gathered}
$$

where $X$ and $Y$ indices mean the first derivation with respect to these parameters and $X X$ and $Y Y$ indices represent the second derivation with respect to these parameters. Equations (2) and (3) are momentum equations in the $x$ - and $y$-directions. In the momentum equation in the Y-direction, there is a buoyancy term due to the gravitational force. There is also a magnetic field force in this equation. Equation (5) is used to non-dimensionalize the equations. Additionally, in Equation (6), the definitions of the Prandtl, $\mathrm{Ra}, \mathrm{Ha}$, and EGN parameters are presented.

$$
\begin{gathered}
\mathrm{X}=\frac{\mathrm{x}}{l}, \mathrm{Y}=\frac{\mathrm{y}}{l}, \mathrm{U}=\frac{\mathrm{u} l}{\alpha_{\mathrm{f}}}, \mathrm{V}=\frac{\mathrm{v} l}{\alpha_{\mathrm{f}}}, \mathrm{P}=\frac{p l^{2}}{\rho_{\mathrm{nf}} \alpha_{\mathrm{f}}^{2}}, \theta=\frac{\mathrm{T}-\mathrm{T}_{\mathrm{c}}}{\mathrm{T}_{\mathrm{h}}-\mathrm{T}_{\mathrm{c}}}, \\
\operatorname{Pr}=\frac{\vartheta_{f}}{\alpha_{f}}, R a=\frac{g \beta_{f} l^{3}\left(\mathrm{~T}_{\mathrm{h}}-\mathrm{T}_{\mathrm{c})} P r\right.}{\vartheta_{f}{ }^{2}}, H a^{2}=\frac{\sigma_{f} B_{0}{ }^{2} l^{2}}{\mu_{f}}, \Lambda=\frac{\mu_{n f} T_{0}}{\mathrm{k}_{f}}\left(\frac{\alpha_{\mathrm{f}}}{L\left(T_{h}-T_{C}\right)}\right)^{2} .
\end{gathered}
$$

To solve the governing equations, boundary conditions must be used. Figure A2 shows the non-dimensionalized boundary conditions. 


\section{All wall: $\mathrm{U}=\mathrm{V}=0$}

\section{Blue wall: $\theta=0$}

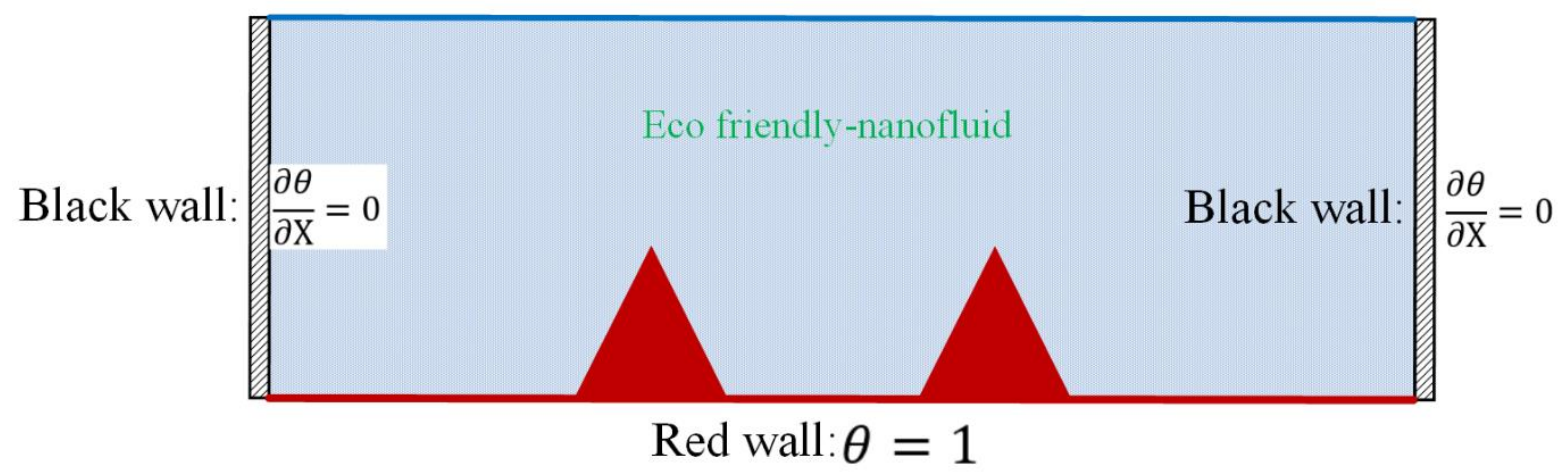

Figure A2. Dimensionless boundary conditions.

The amount of EGN in the general case is defined as follows. The total EGN includes three types of EGN: thermal EGN, EGN due to fluid friction, and EGN due to M-F.

$$
S_{g}=\frac{\mathrm{k}_{n f}}{\mathrm{k}_{f}}\left(\left(\frac{\partial \theta}{\partial \mathrm{X}}\right)^{2}+\left(\frac{\partial \theta}{\partial \mathrm{Y}}\right)^{2}\right)+\Lambda\left\{2\left[\left(\frac{\partial U}{\partial \mathrm{X}}\right)^{2}+\left(\frac{\partial \mathrm{V}}{\partial \mathrm{Y}}\right)^{2}\right]+\left(\frac{\partial \mathrm{U}}{\partial \mathrm{Y}}+\frac{\partial \mathrm{V}}{\partial \mathrm{X}}\right)^{2}\right\}+\Lambda \frac{\sigma_{n f}}{\sigma_{f}} \frac{\mu_{f}}{\mu_{n f}} H a^{2} V^{2} .
$$

The above equation consists of three terms. Temperature changes cause thermal EGN. Velocity changes cause frictional ENG, and velocity changes for different magnetic fields cause magnetic field ENG. The EGN in the enclosure is expressed using the equation below.

$$
\mathrm{S} \_\mathrm{T}=\iint_{0}^{1} S_{g} d X d Y .
$$

The $B e$ is defined as follows:

$$
\begin{aligned}
& B e_{a}=\frac{S_{\text {gen,Thermal }}}{S_{g}}, \\
& B e=\int_{0}^{l} B e d X d Y .
\end{aligned}
$$

\subsection{N-F Properties Equations}

Eco-friendly silver N-Ps are used to make silver N-Fs in a $50 \%$ volume aqueous solution E-G. These N-Ps are obtained from tea leaves in different stages. The following are the relationships that can be used for this N-F [46-48]:

$$
\begin{gathered}
\sigma_{n f}=(1-\varphi) \sigma_{\mathrm{f}}+\varphi \sigma_{p}, \\
\rho_{\mathrm{nf}}=(1-\varphi) \rho_{\mathrm{f}}+\varphi \rho_{p}, \\
(\rho \beta)_{\mathrm{nf}}=(1-\varphi)(\rho \beta)_{\mathrm{f}}+\varphi(\rho \beta)_{p^{\prime}} \\
\left(\rho c_{\mathrm{p}}\right)_{\mathrm{nf}}=(1-\varphi)\left(\rho c_{\mathrm{p}}\right)_{\mathrm{f}}+\varphi\left(\rho c_{\mathrm{p}}\right)_{p^{\prime}} \\
\alpha_{\mathrm{nf}}=\frac{\mathrm{k}_{\mathrm{nf}}}{\left(\rho c_{\mathrm{p}}\right)_{\mathrm{nf}}},
\end{gathered}
$$




$$
\begin{gathered}
\frac{\mu_{n f}}{\mu_{f}}=1-2.5 \varphi, \\
\frac{k_{n f}}{k_{f}}=0.981+0.00114 \times T+30.661 \times \varphi .
\end{gathered}
$$

Correlations related to the thermal conductivity of N-F can be used for the ones with volume fractions up to $1 \%$. Table A1 lists the thermophysical characteristics of E-G and silver N-Ps.

Table A1. Thermophysical properties of water/E-G and Ag [18,47,49-53].

\begin{tabular}{ccccccc}
\hline & $c_{p}(\mathrm{~J} / \mathbf{k g} \cdot \mathbf{K})$ & $\boldsymbol{k}(\mathrm{W} / \mathbf{m} \cdot \mathbf{K})$ & $\boldsymbol{\rho} \mathbf{( \mathbf { k g } / \mathbf { m } ^ { 3 } )}$ & $\mu \mathbf{( k g} / \mathbf{m} \cdot \mathbf{s})$ & $\sigma(\Omega \cdot \mathbf{m})^{-1}$ & 9 \\
\hline E-G & 2430.8 & 0.2532 & 1088 & 0.0141 & $9.2 \times 10^{-5}$ & - \\
\hline Water & 4179 & 0.613 & 997.1 & 0.001 & 0.05 & - \\
\hline Ag & 235 & 429 & 10,500 & - & $1.6 \times 10^{-4}$ & 40 \\
\hline
\end{tabular}

\subsection{Numerical Procedure}

To solve dimensionless equations, the equations are first algebraized using the volume control method. Then, a home code is written in FORTRAN software to solve dimensionless equations using the SIMPLE algorithm with the help of boundary conditions. In this software, a structured mesh is generated. The convergence criterion to solve all equations, including continuity, momentum, and energy equations, is $10^{-8}$. Grid study and validation are performed, and the results are presented in the Appendix A.

\section{Results and Discussion}

Figure $\mathrm{A} 3$ demonstrates the effect of $\mathrm{Ra}$ and $\mathrm{Ha}$ on the velocity field for $\mathrm{H}=\mathrm{W}=$ 0.2 . It can be seen that an enhancement in the Ha has a strong effect on the contours and reduces the amount of velocity. An increment in the Ra enhances the velocity. Changing the number of vortices from two to four vortices is another effect of changing Ra and Ha on the velocity field.

\section{$\mathrm{Ra}=10^{3}$}
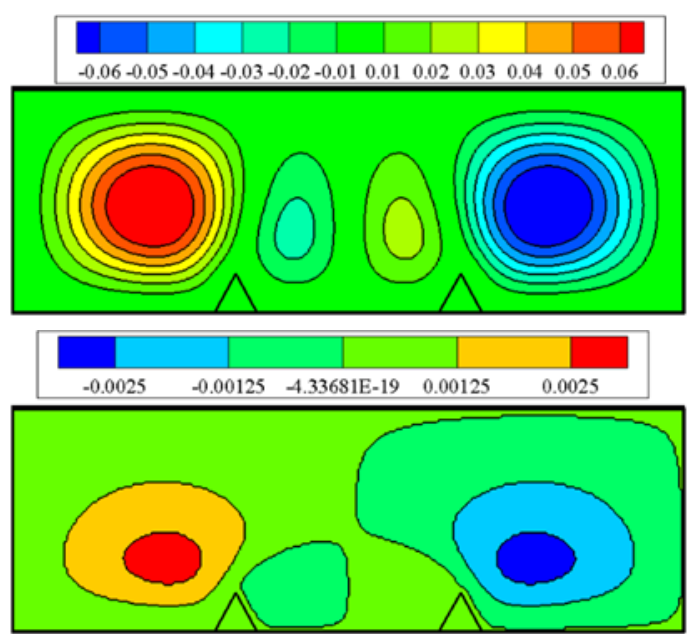

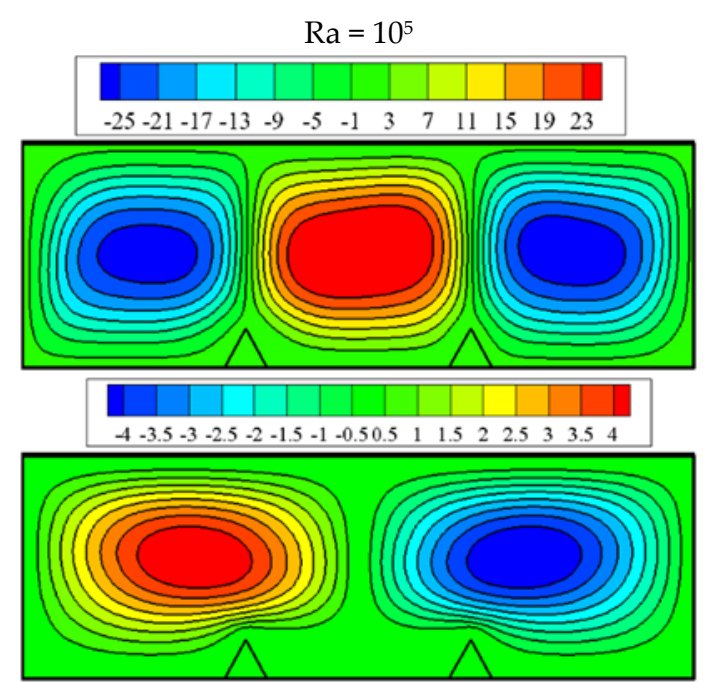

Figure A3. The effect of $\mathrm{Ra}$ and $\mathrm{Ha}$ on the velocity field for $\mathrm{H}=\mathrm{W}=0.2$.

Figure A4 reveals the effect of $\mathrm{Ra}$ and $\mathrm{Ha}$ on the temperature field for $\mathrm{H}=\mathrm{W}=0.2$ and a volume fraction of $0.3 \%$. In the case of low $\mathrm{Ra}$, the isotherms do not change with the $\mathrm{Ha}$ and remain as parallel lines. However, for $\mathrm{Ra}=10^{5}$, the variations of the Ha affect the isotherms and change their shape. The changes of the Ra also affect the temperature contours, changing it from parallel lines to overlapping ones. 
$\mathrm{Ha}$

0

40

$\mathrm{Ha}$

0

40

\section{0}

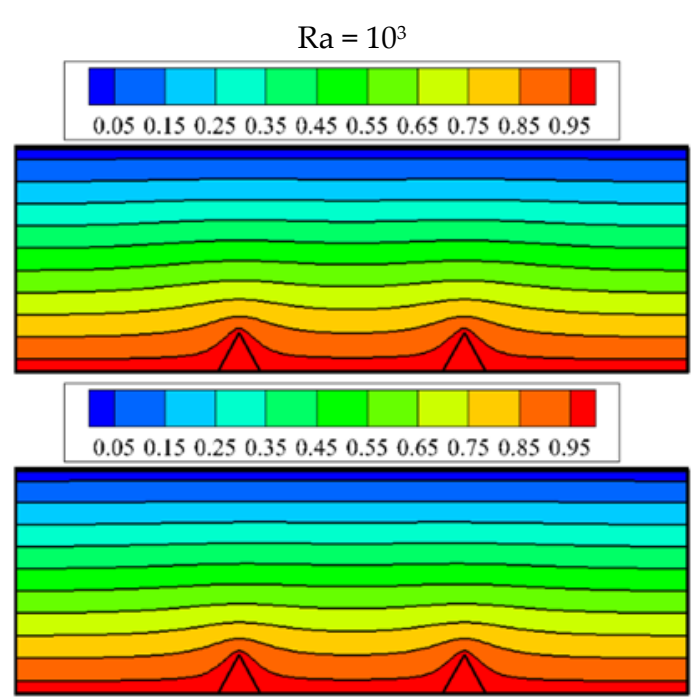

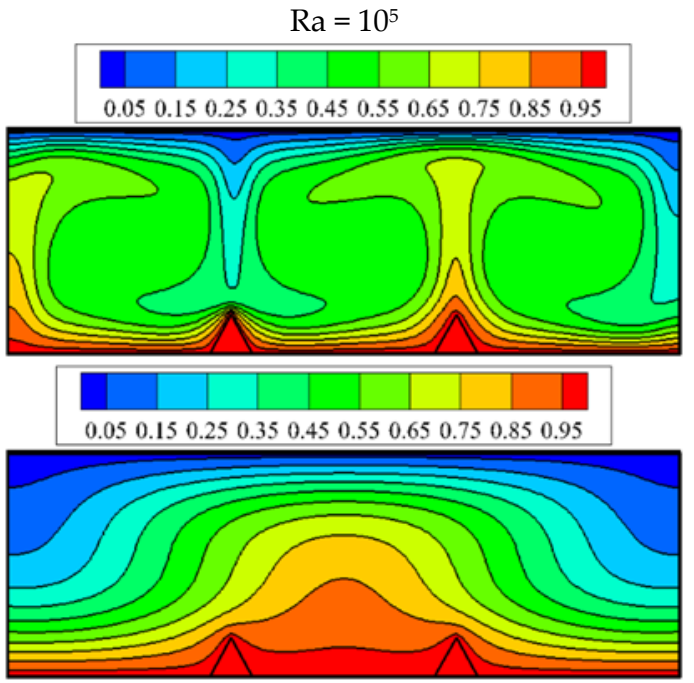

Figure A4. The effect of $\mathrm{Ra}$ and $\mathrm{Ha}$ on the temperature field for $\mathrm{H}=\mathrm{W}=0.2$ and a volume fraction of $0.3 \%$.

Figure A5 shows the effect of Ra and Ha on the EGN for $\mathrm{H}=\mathrm{W}=0.2$ and a volume fraction of $0.3 \%$. At low Ra. The variations of the Ha do not affect the place of EGN and the values of EN. However, at $\mathrm{Ra}=10^{5}$, the Ha affects the place of EGN and the values of EN. High EGN occurs at the blade tip in all figures. Numerical values for $\mathrm{Ra}=10^{5}$ and the absence of the M-F are much larger than the other cases.
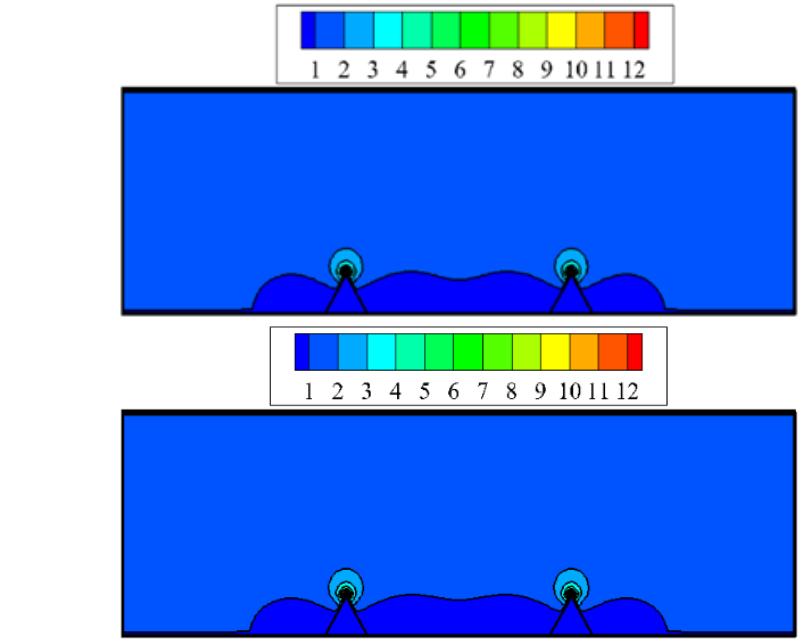
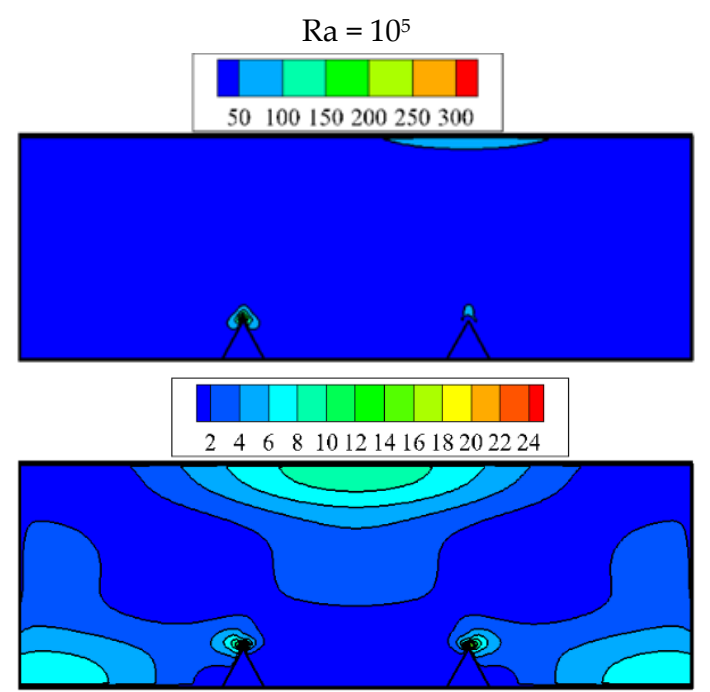

Figure A5. Effect of Ra and Ha on the EGN for $\mathrm{H}=\mathrm{W}=0.2$ and a volume fraction of $0.3 \%$.

Figure A6 demonstrates the EGN for different Ra and Ha when $\mathrm{W}=0.5, \mathrm{H}=0.7$, and the volume fraction is $0.3 \%$. An enhancement in the Ra due to an increase in the velocity and an increment in the sudden changes in the temperature enhances the EGN. However, an increase in the Ha reduces the EGN due to the reduction in the velocity. Obviously, at $\mathrm{Ra}=10^{5}$, where the velocity is higher, and the increase in Ha has a greater effect on the deceleration, the decrease in the EGN is lower. Thus, the maximum EGN corresponds to $\mathrm{Ra}=10^{5}$ in the absence of the M-F. 


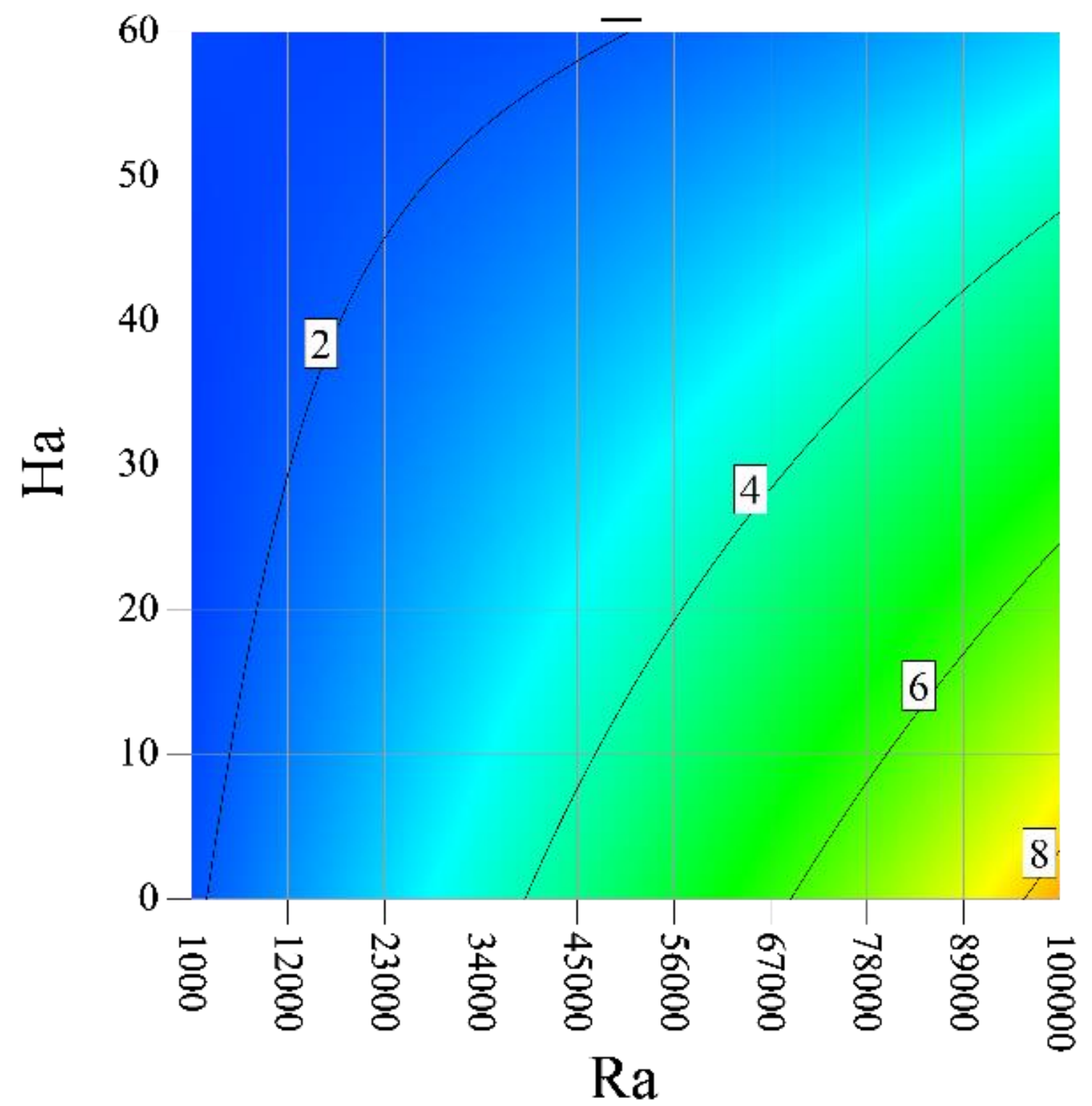

Figure A6. EGN for different Ra and Ha when $\mathrm{W}=0.5, \mathrm{H}=0.7$, and the volume fraction is $0.3 \%$.

Figure A7 shows the EGN for different Ra and various blade heights when $\mathrm{Ha}=30$, $\mathrm{H}=0.7$, and volume fraction is $0.3 \%$. The trend of EGN changes with the Ra is an increasing trend. The EGN is enhanced with the height, which has less of an effect on EGN than the Ra. The enlargement of the blade causes sudden changes in temperature as well as velocity, producing irreversibility and an increase in EGN.

Figure A8 shows the EGN for different $\mathrm{Ra}$ and various blade lengths when $\mathrm{Ha}=30$, $\mathrm{W}=0.5$, and the volume fraction is $0.3 \%$. The increasing trend of EGN with the Ra is observed. The change in blade length, however, has different effects on EGN at different Ra. At low Ra, an increase in the blade length first increases and then decreases EGN. While, at Ra greater than 45,000 , the increase in blade length prevents a constant enhancing trend in EN. At Ra $=10^{5}$, the EGN is enhanced with the blade length. 


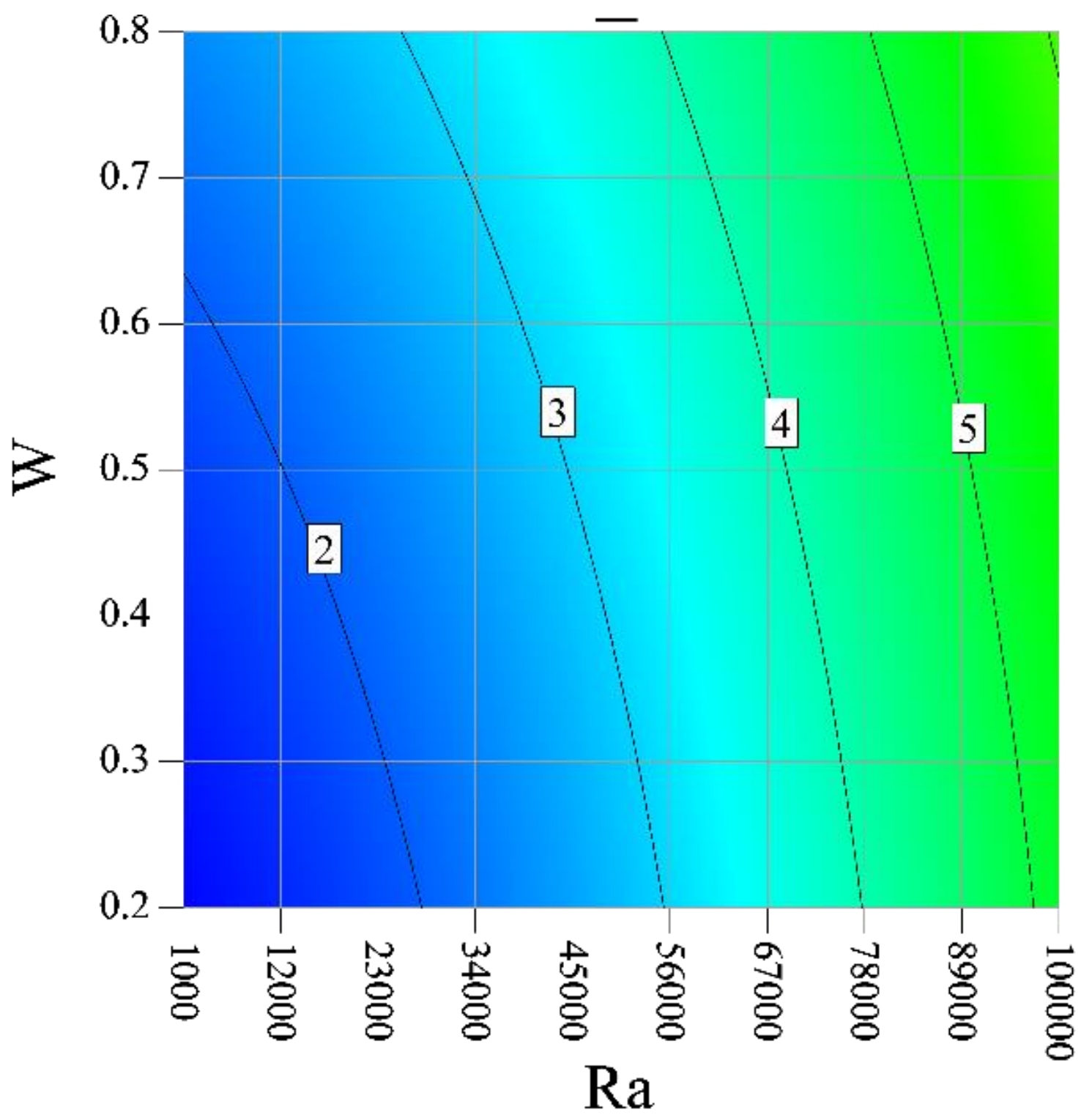

Figure A7. EGN for different $\mathrm{Ra}$ and various blade heights when $\mathrm{Ha}=30, \mathrm{H}=0.7$, and the volume fraction is $0.3 \%$.

Figure A9 shows the entropy for different Ha and various blade heights when $\mathrm{Ra}=10^{5}$, $\mathrm{H}=0.7$, and volume fraction is $0.3 \%$. As the Ha is enhanced, the amount of EGN is reduced. In addition, for all $\mathrm{Ha}$ and various strengths of the $\mathrm{M}-\mathrm{F}$, an increase in the blade height enhances the amount of EGN. The amount of EGN changes with the blade height has a constant trend for all Ha. The lowest EGN occurs at $\mathrm{Ha}=60$ and $\mathrm{W}=0.2$.

Figure A10 shows the EGN for different Ha and various blade lengths when $\mathrm{Ra}=10^{5}$, $\mathrm{W}=0.7$, and the volume fraction is $0.3 \%$. As the Ha is enhanced, the amount of EGN is reduced. An increase in the blade length reduces the EGN for lower Ha and weaker M-Fs. But, at high Ha and strong M-Fs, the enhancement of the blade length increases the EGN initially and then decreases. The highest EGN corresponds to $\mathrm{Ha}=0$ and the blade length of 0.2 . 


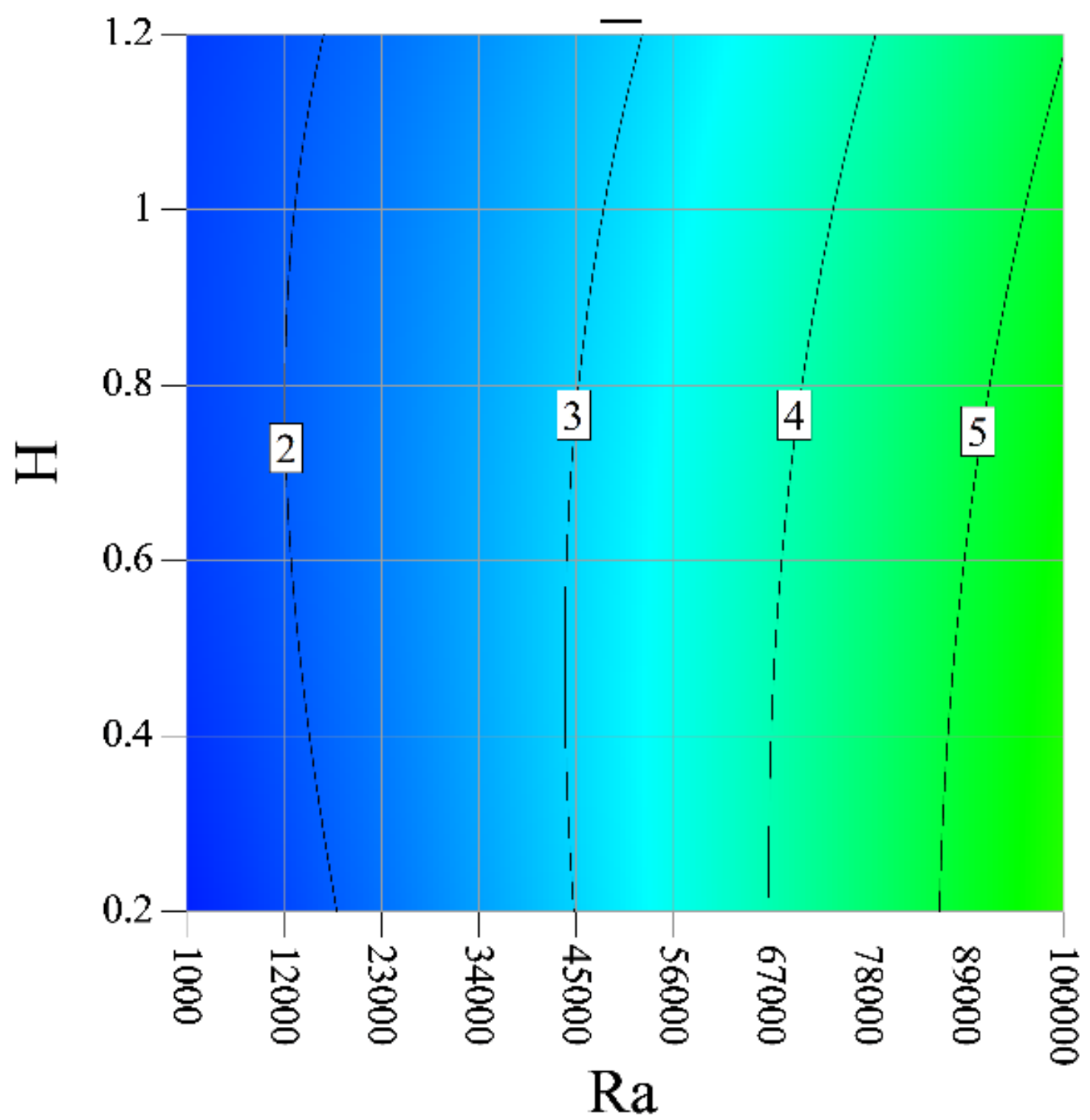

Figure A8. EGN for different $\mathrm{Ra}$ and various blade lengths when $\mathrm{Ha}=30, \mathrm{~W}=0.5$, and the volume fraction is $0.3 \%$.

Figure A11 shows the EGN for different blade heights and lengths when $\mathrm{Ra}=10^{5}$, $\mathrm{Ha}=30$, and the volume fraction is $0.3 \%$. The variations of EGN with the blade height have an increasing trend so that for all blade lengths, increasing its height enhances the amount of EGN. An increment in the length of the blade initially enhances the EGN slightly and then reduces the EGN so that the EGN prevents the increasing trend to $\mathrm{W}=0.4$, and then the trend is reversed. The minimum EGN occurs at $\mathrm{W}=1.2$ and $\mathrm{H}=0.2$, while the maximum one occurs at $\mathrm{W}=0.4$ and $\mathrm{H}=0.8$.

Figure A12 illustrates the Be for different Ra and Ha when $\mathrm{W}=0.5$ and $\mathrm{H}=0.7$, and the volume fraction is $0.3 \%$. The Be has a constant decreasing trend with the Ra, while the Be is reduced and is enhanced with the Ha. This trend is more visible at low Ra. At high $\mathrm{Ra}$, an increasing trend takes place for the Be. The minimum value of the Be occurs at $\mathrm{Ra}=$ $10^{5}$ while its maximum occurs at $\mathrm{Ra}=10^{3}$ and $\mathrm{Ha}=60$. 


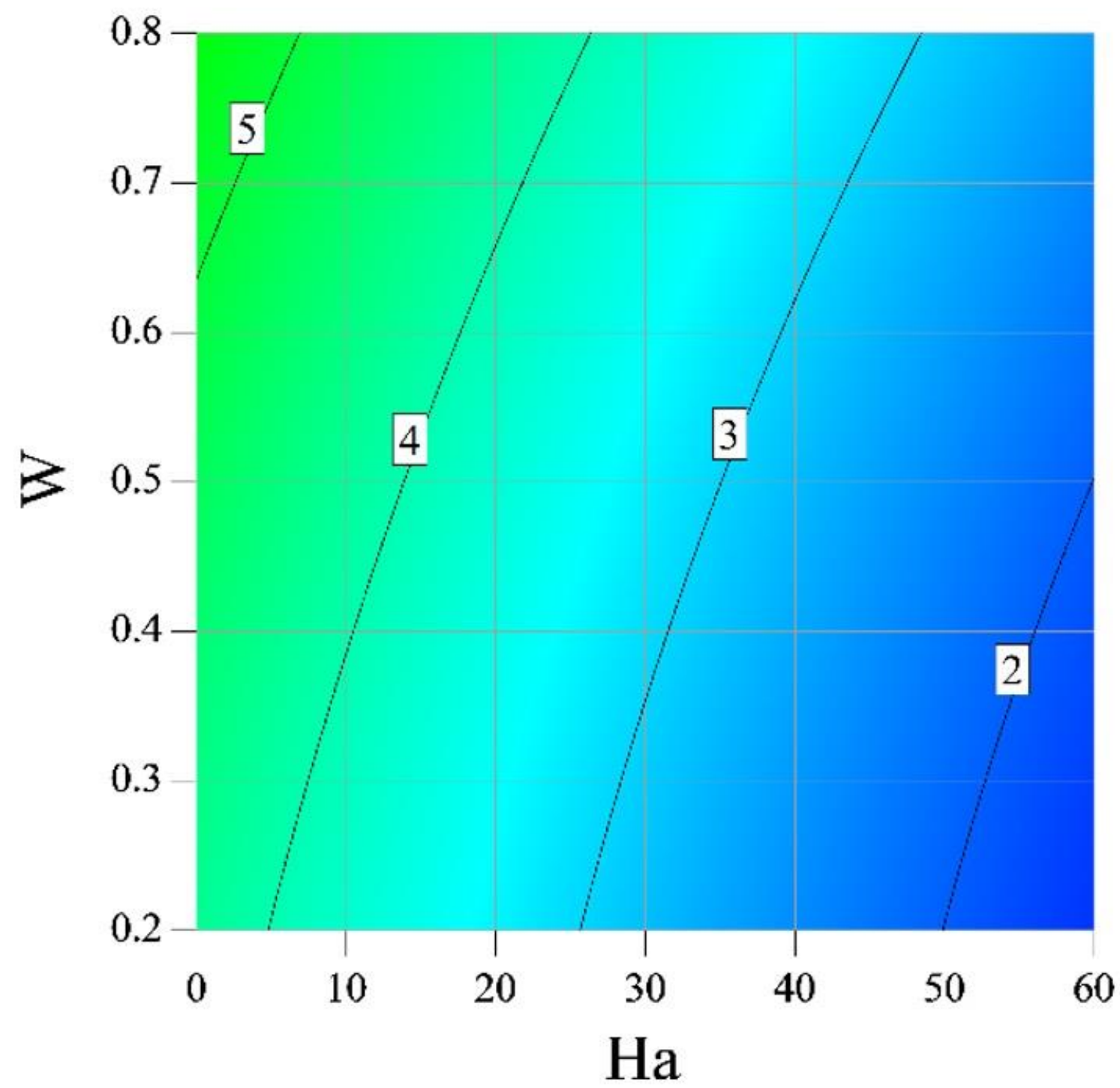

Figure A9. EGN for different $\mathrm{Ha}$ and various blade heights when $\mathrm{Ra}=10^{5}, \mathrm{H}=0.7$, and the volume fraction is $0.3 \%$.

Figure A13 demonstrates the Be for different Ra and various blade heights when $\mathrm{H}=0.7$ and $\mathrm{Ha}=30$, and the volume fraction is $0.3 \%$. It can be seen that the variation of the $\mathrm{Be}$ is under a decreasing trend with the $\mathrm{Ra}$, but changing the blade height has a different effect on the Be, so that for high and low Ra, changing the blade height has a different impact on the Be. For high $\mathrm{Ra}$, an enhancement in the blade height first intensifies the Be and then reduces it, while at low $\mathrm{Ra}$, an increment in the blade height reduces the Be.

Figure A14 reveals the EGN for different Ra and various blade heights when $\mathrm{H}=$ 0.7 and $\mathrm{Ha}=30$, and volume fraction is $0.3 \%$. The variations of the Be with the blade length have a constant decreasing trend so that an increase in the blade length reduces the amount of Be for all Ra. The declining trend of the Be is maintained with the Ra for various blade lengths. 


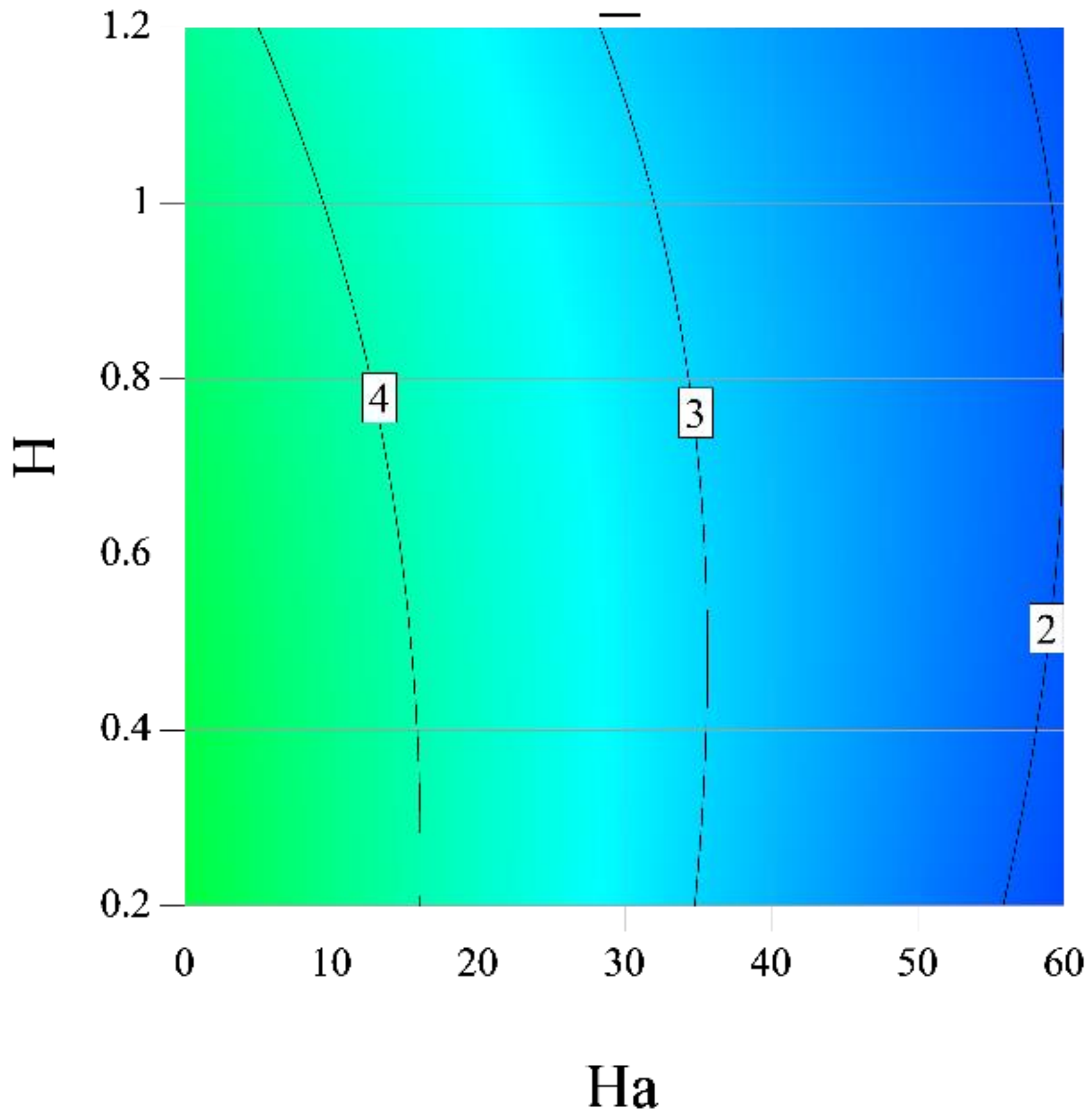

Figure A10. EGN for different Ha and various blade lengths when $\mathrm{Ra}=10^{5}, \mathrm{~W}=0.7$, and the volume fraction is $0.3 \%$.

Table A2 presents the EGN for different volume percentages of silver eco-friendly $\mathrm{N}-\mathrm{Ps}$ at $\mathrm{Ra}=10^{5}, \mathrm{Ha}=0$, and $\mathrm{W}=\mathrm{H}=0.2$. It is observed that an increment in the amount of silver eco-friendly N-Ps in the fluid enhances the amount of EGN. Improving the heat transfer by adding silver N-Ps causes the temperature changes in the enclosure to intensify, and as a result, the amount of EGN, especially thermal EGN, is enhanced. For instance, the addition of $0.5 \%$ silver N-Ps to a mixture of water and E-G results in an enhancement in the EGN by $6.2 \%$ compared to the base fluid. 


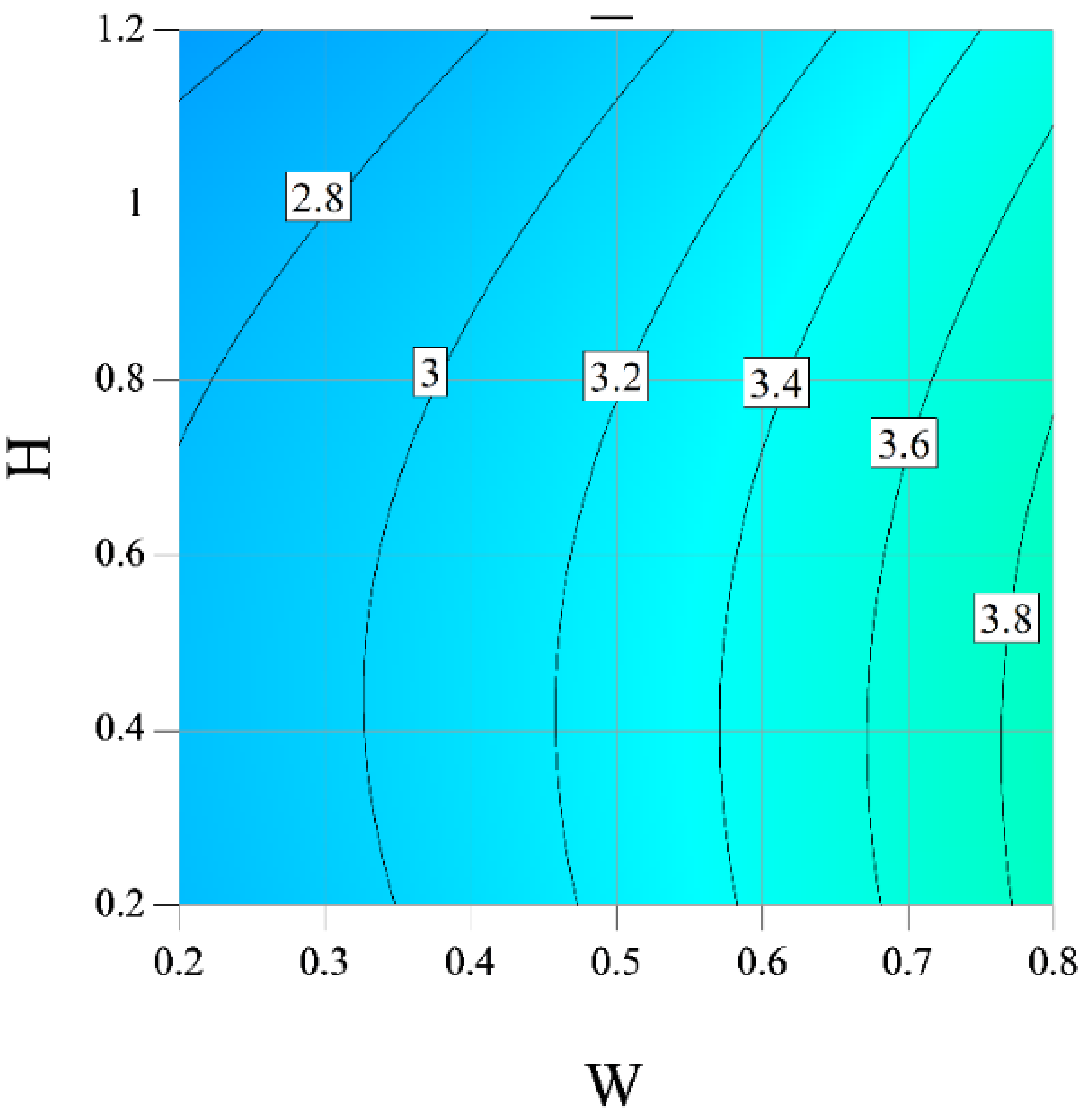

Figure A11. EGN for different blade heights and lengths when $\mathrm{Ra}=10^{5}, \mathrm{Ha}=30$, and the volume fraction is $0.3 \%$.

Table A2. The EGN for different volume percentages of silver eco-friendly N-Ps at Ra $=105, \mathrm{Ha}=0$, and $\mathrm{W}=\mathrm{H}=0.2$.

\begin{tabular}{ccc}
\hline $\boldsymbol{\varphi}$ & S_T $_{-}$ & $\frac{\text { S_T}_{\varphi}-\mathbf{S}_{-} \mathbf{T}_{\varphi=0}}{\mathbf{S}_{-} \mathbf{T}_{\varphi=0}}$ \\
\hline 0 & 8.02 & 0 \\
0.1 & 8.02 & 1.7 \\
0.2 & 8.02 & 2.8 \\
0.3 & 8.02 & 3.8 \\
0.4 & 8.02 & 4.4 \\
0.5 & 8.02 & 6.2 \\
\hline
\end{tabular}




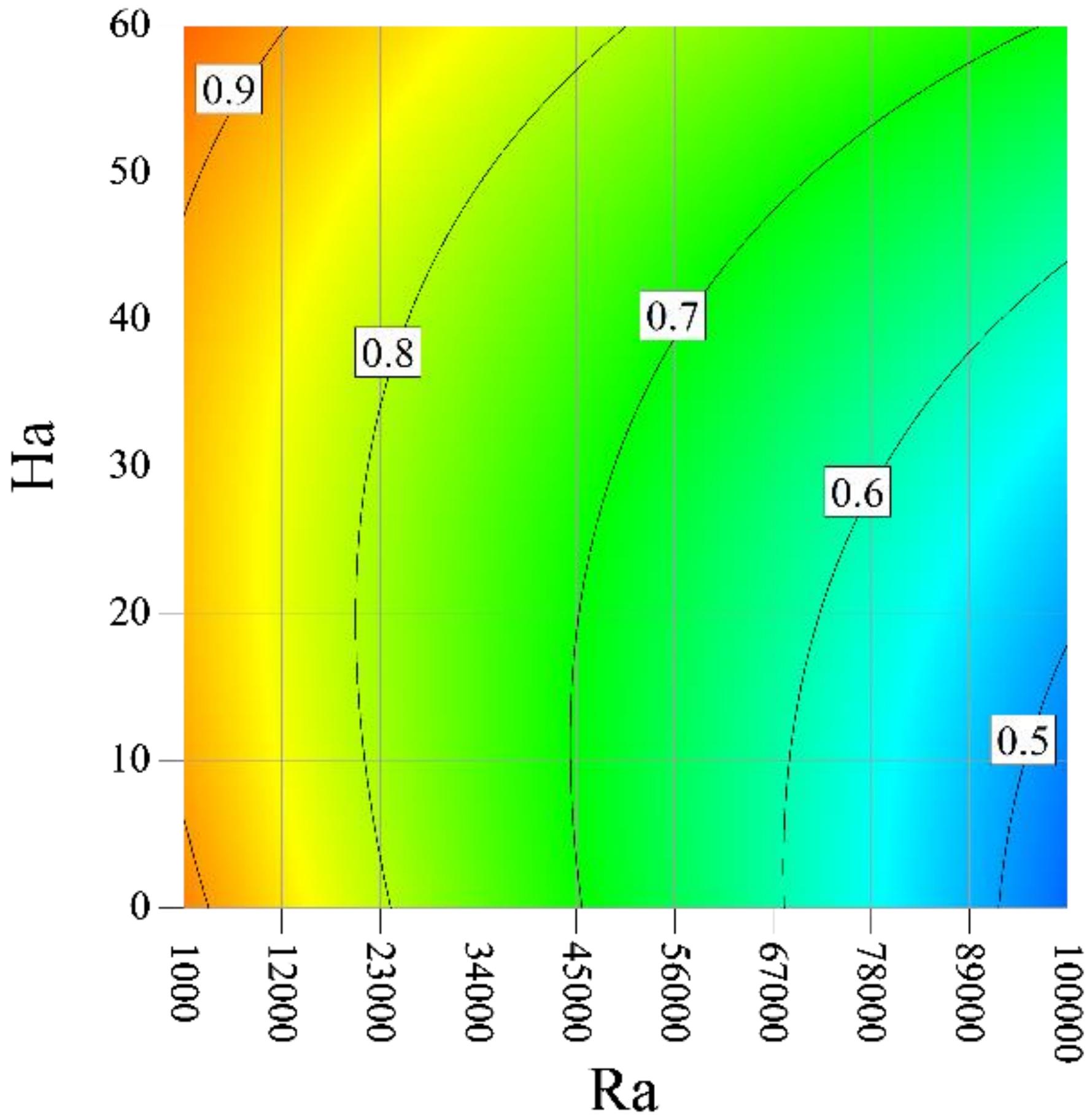

Figure A12. Be for different Ra and $\mathrm{Ha}$ when $\mathrm{W}=0.5$ and $\mathrm{H}=0.7$, and volume fraction is $0.3 \%$. 


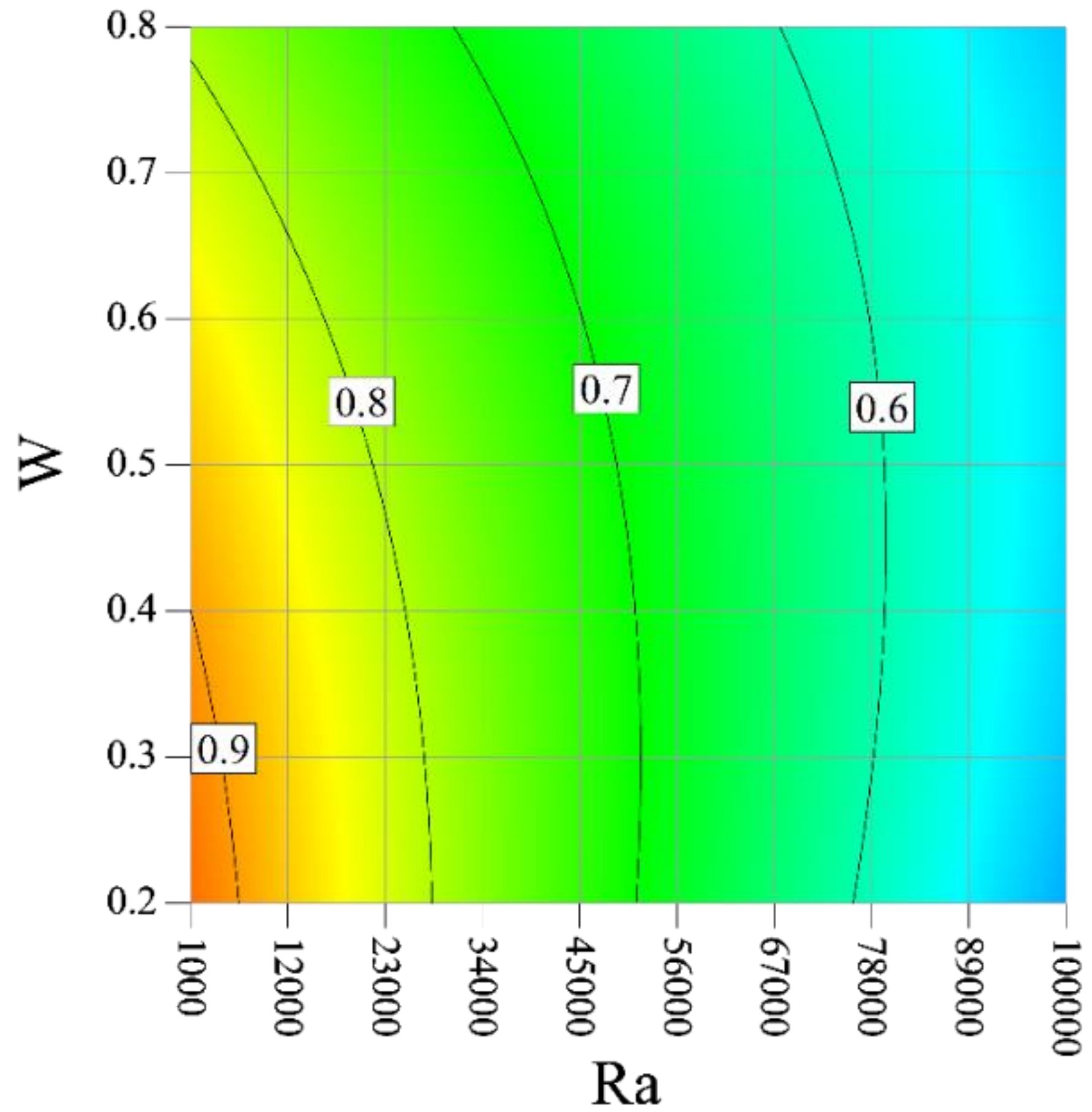

Figure A13. Be for different Ra and various blade heights when $\mathrm{H}=0.7$ and $\mathrm{Ha}=30$, and the volume fraction is $0.3 \%$. 


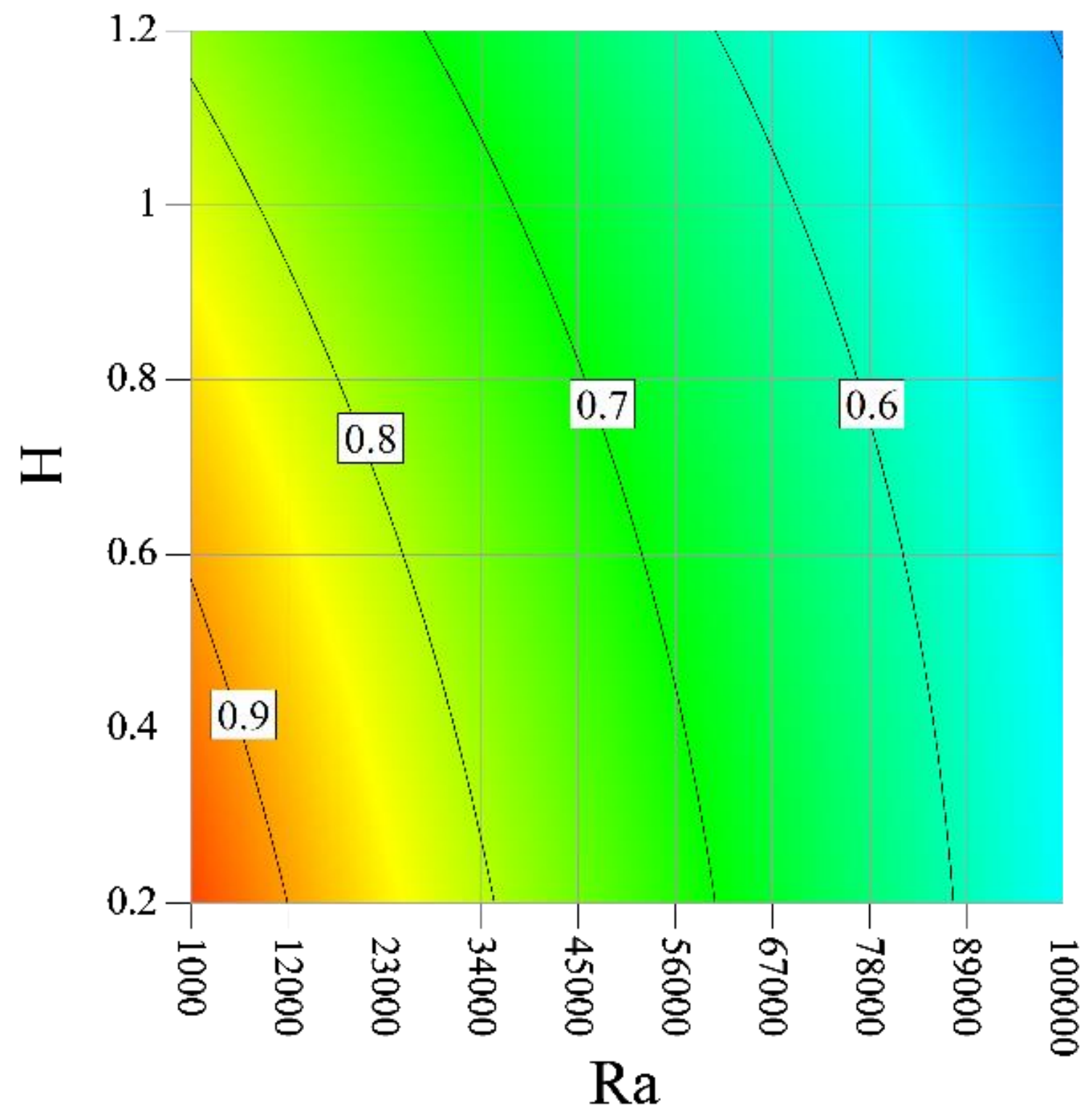

Figure A14. EGN for different $\mathrm{Ra}$ and various blade lengths when $\mathrm{W}=0.5$ and $\mathrm{Ha}=30$, and the volume fraction is $0.3 \%$.

Equation (16) is a correlation to express the total EGN in terms of the Ra, the Ha, and the blade length and height.

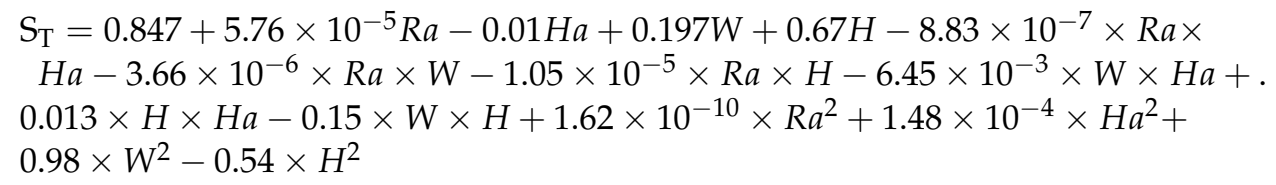

It is noteworthy that an increment in ENG in different heat exchangers is undesirable. Enhancing ENG in the enclosure results in an enhancement of irreversibility. Increasing ENG ultimately leads to an intensification of energy loss. Thus, it is attempted to reduce the ENG in different devices so that the irreversibility is reduced, and the efficiency of the devices is enhanced. Using the above relation, it can be found how many variable parameters can have the minimum ENG in the enclosure.

\section{Conclusions}

In this paper, the EGN in a rectangular enclosure saturated with an eco-friendly N-F containing silver N-Ps dispersed in an equal mixture of water and E-G was evaluated. The 
triangular blades were installed on the bottom of the enclosure when a M-F was applied in the $\mathrm{x}$-direction. By changing the percentage of silver N-Ps, blade dimensions, as well as Ra and $\mathrm{Ha}$, the EGN and the Be were calculated, and the following results were obtained.

1. The addition of silver eco-friendly N-Ps to a mixture of water and E-G enhances the amount of EGN, so that adding $0.3 \%$ of N-F enhances the amount of EGN by 3.8\%;

2. An increment in the Ra enhances ENG and reduces the Be. The ENG has a decreasing trend with the Ha;

3. An enhancement in the blade height causes the amount of EGN to enhance. An increment in the blade height results in a reduction in the Be at the low $\mathrm{Ra}$, but the Be is first enhanced and reduced at high Ra;

4. The increase of Ha at high Ra leads to an increase in the Be, but at low Ras, the Be first has a decreasing trend and then an increasing trend;

5. Enhancing the fin length in strong convections decreases the ENG. An increment in the fin length results in a reduction in the Be.

Author Contributions: Data curation, Y.K. and H.M.A.-D.; Formal analysis, Y.K.; Investigation, H.M.A.-D. and A.K.A.; Methodology, Y.K. and A.K.A. and S.M.S.; Supervision, M.S. and G.C.; Writing—original draft, Y.K. and A.K.A.; Writing—review \& editing, M.S. and G.C.; Conceptualization, M.S. and G.C. All authors have read and agreed to the published version of the manuscript.

Funding: This research received no external funding.

Institutional Review Board Statement: Not applicable.

Informed Consent Statement: Not applicable.

Data Availability Statement: Not applicable.

Acknowledgments: This work was supported by the Taif University Researchers Supporting grant number (TURSP-2020/266) of Taif University, Taif, Saudi Arabia.

Conflicts of Interest: The authors declare no conflict of interest.

\section{Nomenclature}

$B_{0} \quad$ Magnetic Field Strength

Be Bejan number

$C_{\mathrm{p}} \quad$ Specific heat $[\mathrm{J} /(\mathrm{kg} \cdot \mathrm{K})]$

$g \quad$ Gravitational acceleration $\left[\mathrm{m} / \mathrm{s}^{2}\right]$

$h \quad$ Convection heat transfer coefficient $\left[\mathrm{w} /\left(\mathrm{m}^{2} \cdot \mathrm{K}\right)\right]$

$H \quad$ Obstacle non-dimensional length

$\mathrm{Ha}$ Hartmann number

$k \quad$ Thermal conductivity $[\mathrm{W} /(\mathrm{m} \cdot \mathrm{K})]$

$l \quad$ Enclosure length [m]

$L \quad$ Enclosure non-dimensional length

$\mathrm{Nu}$ Nusselt number

$p \quad$ Pressure $[\mathrm{Pa}]$

Non-dimensional

$P \quad$ Prandtl number $\left(\vartheta_{\mathrm{f}} / \alpha_{\mathrm{f}}\right)$

$\operatorname{Pr} \quad$ Rayleigh number $\left(g \beta_{\mathrm{f}} l^{3}\left(\mathrm{~T}_{\mathrm{h}}-\mathrm{T}_{\mathrm{c})} / \alpha_{\mathrm{f}} \vartheta_{f}\right)\right.$

$R a$ entropy generation $[\mathrm{W} / \mathrm{K}]$

S_T Temperature [K]

$T \quad$ Velocity component $\left(U=u l / \alpha_{\mathrm{f}}, V=v l / \alpha_{\mathrm{f}}\right)$

$U, V \quad$ Obstacle non-dimensional height

$W \quad$ Coordinates $(X=x / l, Y=y / l)$

$X, Y \quad$ Coordinates $(X=x / l, Y=y / l)$ 


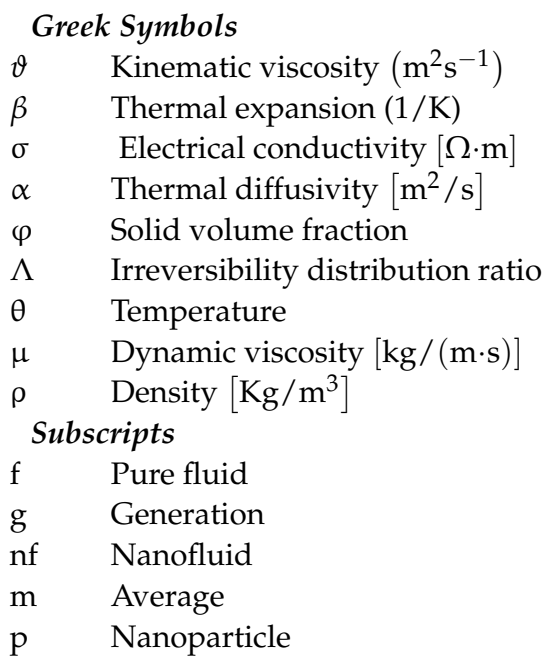

\section{Appendix A}

To perform the grid independence test, various studies were performed for different blade conditions. Finally, by examining the amount of EGN for different grids (Table A1), a grid resolution of $450 \times 150$ was selected for the simulations.

Table A1. Shows the influence of the number of grid points on total EGN when $\mathrm{Ra}=10^{5}$ and $\mathrm{Ha}=0$ and the blade length and height are both 0.2 .

\begin{tabular}{cc}
\hline Grid & S_T \\
\hline $120 \times 360$ & 8.98 \\
$130 \times 390$ & 8.68 \\
$140 \times 420$ & 8.43 \\
$150 \times 450$ & 8.33 \\
$160 \times 480$ & 8.33 \\
\hline
\end{tabular}

The simulations are required to validate using previous numerical or experimental results. For this purpose, it is necessary to simulate one of the previously presented works in the same way and compare the results with the previous ones. Various validations are performed to validate the code written for the present study, leading to reasonable results. For example, one of these validations performed with the results of Pirmohammadi and Ghassemi [54] is shown in Figure A1. In this validation, the average Nu at different Ha is calculated. The findings of the current simulations are consistent with those published by Pirmohammadi and Ghassemi [54], as shown in the Figure A1. 


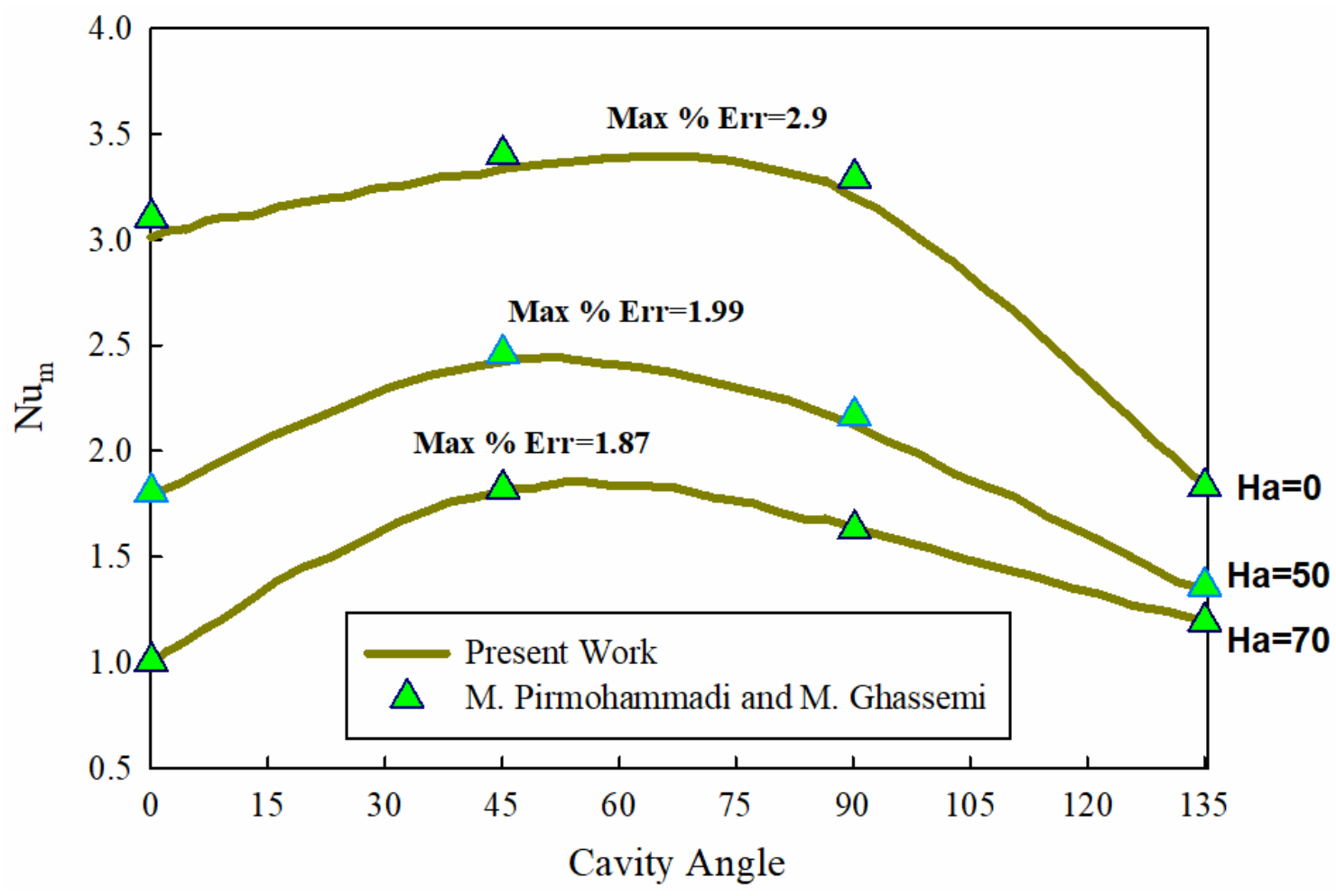

Figure A1. Average Nu versus cavity angle for different Ha.

\section{References}

1. Li, X.; Feng, Y.; Liu, B.; Yi, D.; Yang, X.; Zhang, W.; Chen, G.; Liu, Y.; Bai, P. Influence of NbC particles on microstructure and mechanical properties of AlCoCrFeNi high-entropy alloy coatings prepared by laser cladding. J. Alloys Compd. 2019, 788, 485-494. [CrossRef]

2. Wang, H.; Wang, M.; Tang, Y. A novel zinc-ion hybrid supercapacitor for long-life and low-cost energy storage applications. Energy Storage Mater. 2018, 13, 1-7. [CrossRef]

3. Zhang, X.; Tang, Y.; Zhang, F.; Lee, C.-S. A Novel Aluminum-Graphite Dual-Ion Battery. Adv. Energy Mater. 2016, 6, 1502588. [CrossRef]

4. Fan, Z.; Ji, P.-p.; Zhang, J.; Segets, D.; Chen, D.-R.; Chen, S.-C. Wavelet neural network modeling for the retention efficiency of sub-15 nm nanoparticles in ultrafiltration under small particle to pore diameter ratio. J. Membr. Sci. 2021, 635, 119503. [CrossRef]

5. Cui, X.; Li, C.; Ding, W.; Chen, Y.; Mao, C.; Xu, X.; Liu, B.; Wang, D.; Li, H.N.; Zhang, Y.; et al. Minimum quantity lubrication machining of aeronautical materials using carbon group nanolubricant: From mechanisms to application. Chin. J. Aeronaut. 2021. [CrossRef]

6. Yan, S.-R.; Aghakhani, S.; Karimipour, A. Influence of a membrane on nanofluid heat transfer and irreversibilities inside a cavity with two constant-temperature semicircular sources on the lower wall: Applicable to solar collectors. Phys. Scr. 2020, 95, 085702. [CrossRef]

7. Eshgarf, H.; Kalbasi, R.; Maleki, A.; Shadloo, M.S.; Karimipour, A. A review on the properties, preparation, models and stability of hybrid nanofluids to optimize energy consumption. J. Therm. Anal. Calorim. 2021, 144, 1959-1983. [CrossRef]

8. Ghalandari, M.; Maleki, A.; Haghighi, A.; Shadloo, M.S.; Nazari, M.A.; Tlili, I. Applications of nanofluids containing carbon nanotubes in solar energy systems: A review. J. Mol. Liq. 2020, 313, 113476. [CrossRef]

9. Komeilibirjandi, A.; Raffiee, A.H.; Maleki, A.; Nazari, M.A.; Shadloo, M.S. Thermal conductivity prediction of nanofluids containing $\mathrm{CuO}$ nanoparticles by using correlation and artificial neural network. J. Therm. Anal. Calorim. 2020, 139, 2679-2689. [CrossRef]

10. Wang, N.; Maleki, A.; Nazari, M.A.; Tlili, I.; Shadloo, M.S. Thermal Conductivity Modeling of Nanofluids Contain MgO Particles by Employing Different Approaches. Symmetry 2020, 12, 206. [CrossRef]

11. Afrand, M.; Pordanjani, A.H.; Aghakhani, S.; Oztop, H.F.; Abu-Hamdeh, N. Free convection and entropy generation of a nanofluid in a tilted triangular cavity exposed to a magnetic field with sinusoidal wall temperature distribution considering radiation effects. Int. Commun. Heat Mass Transf. 2020, 112, 104507. [CrossRef]

12. Shahsavani, E.; Afrand, M.; Kalbasi, R. Using experimental data to estimate the heat transfer and pressure drop of non-Newtonian nanofluid flow through a circular tube: Applicable for use in heat exchangers. Appl. Therm. Eng. 2018, 129, 1573-1581. [CrossRef] 
13. Ghodsinezhad, H.; Sharifpur, M.; Meyer, J.P. Experimental investigation on cavity flow natural convection of $\mathrm{Al}_{2} \mathrm{O}_{3}-\mathrm{water}$ nanofluids. Int. Commun. Heat Mass Transf. 2016, 76, 316-324. [CrossRef]

14. Sharifpur, M.; Solomon, A.B.; Ottermann, T.L.; Meyer, J.P. Optimum concentration of nanofluids for heat transfer enhancement under cavity flow natural convection with $\mathrm{TiO}_{2}$-Water. Int. Commun. Heat Mass Transf. 2018, 98, 297-303. [CrossRef]

15. Solomon, A.B.; van Rooyen, J.; Rencken, M.; Sharifpur, M.; Meyer, J.P. Experimental study on the influence of the aspect ratio of square cavity on natural convection heat transfer with $\mathrm{Al}_{2} \mathrm{O}_{3}$ /Water nanofluids. Int. Commun. Heat Mass Transf. 2017, 88, 254-261. [CrossRef]

16. Ghasemi, B.; Aminossadati, S. Natural convection heat transfer in an inclined enclosure filled with a water-CuO nanofluid. Numer. Heat Transf. Part A Appl. 2009, 55, 807-823. [CrossRef]

17. Cheng, F.; Betts, J.W.; Kelly, S.M.; Schaller, J.; Heinze, T. Synthesis and antibacterial effects of aqueous colloidal solutions of silver nanoparticles using aminocellulose as a combined reducing and capping reagent. Green Chem. 2013, 15, 989-998. [CrossRef]

18. Mashayekhi, R.; Khodabandeh, E.; Bahiraei, M.; Bahrami, L.; Toghraie, D.; Akbari, O.A. Application of a novel conical strip insert to improve the efficacy of water-Ag nanofluid for utilization in thermal systems: A two-phase simulation. Energy Convers. Manag. 2017, 151, 573-586. [CrossRef]

19. Essa, F.A.; Elsheikh, A.H.; Algazzar, A.A.; Sathyamurthy, R.; Ali, M.K.A.; Elaziz, M.A.; Salman, K.H. Eco-friendly coffee-based colloid for performance augmentation of solar stills. Process. Saf. Environ. Prot. 2020, 136, 259-267. [CrossRef]

20. Kosinska, A.; Balakin, B.V.; Kosinski, P. Use of biodegradable colloids and carbon black nanofluids for solar energy applications. AIP Adv. 2021, 11, 055214. [CrossRef]

21. Kalimuthu, K.; Cha, B.S.; Kim, S.; Park, K.S. Eco-friendly synthesis and biomedical applications of gold nanoparticles: A review. Microchem. J. 2020, 152, 104296. [CrossRef]

22. Aghakhani, S.; Ghasemi, B.; Pordanjani, A.H.; Wongwises, S.; Afrand, M. Effect of replacing nanofluid instead of water on heat transfer in a channel with extended surfaces under a magnetic field. Int. J. Numer. Methods Heat Fluid Flow 2019, 24, $1249-1271$. [CrossRef]

23. Afrand, M.; Farahat, S.; Nezhad, A.H.; Sheikhzadeh, G.A.; Sarhaddi, F. Numerical Simulation of Electrically Conducting Fluid Flow And Free Convective Heat Transfer In An Annulus On Applying A Magnetic Field. Heat Transf. Res. 2014, 45, 749-766. [CrossRef]

24. Afrand, M.; Farahat, S.; Nezhad, A.H.; Sheikhzadeh, G.A.; Sarhaddi, F. 3-D numerical investigation of natural convection in a tilted cylindrical annulus containing molten potassium and controlling it using various magnetic fields. Int. J. Appl. Electromagn. Mech. 2014, 46, 809-821. [CrossRef]

25. Tian, M.-W.; Rostami, S.; Aghakhani, S.; Goldanlou, A.S.; Qi, C. A techno-economic investigation of 2D and 3D configurations of fins and their effects on heat sink efficiency of MHD hybrid nanofluid with slip and non-slip flow. Int. J. Mech. Sci. 2021, 189, 105975. [CrossRef]

26. Giwa, S.O.; Sharifpur, M.; Meyer, J.P. Effects of uniform magnetic induction on heat transfer performance of aqueous hybrid ferrofluid in a rectangular cavity. Appl. Therm. Eng. 2020, 170, 115004. [CrossRef]

27. Sheikholeslami, M.; Hayat, T.; Muhammad, T.; Alsaedi, A. MHD forced convection flow of nanofluid in a porous cavity with hot elliptic obstacle by means of Lattice Boltzmann method. Int. J. Mech. Sci. 2018, 135, 532-540. [CrossRef]

28. Mahmoudi, A.; Mejri, I.; Abbassi, M.A.; Omri, A. Lattice Boltzmann simulation of MHD natural convection in a nanofluid-filled cavity with linear temperature distribution. Powder Technol. 2014, 256, 257-271. [CrossRef]

29. Ghasemi, B.; Aminossadati, S.; Raisi, A. Magnetic field effect on natural convection in a nanofluid-filled square enclosure. Int. J. Therm. Sci. 2011, 50, 1748-1756. [CrossRef]

30. Hu, Y.; Qing, J.x.; Liu, Z.H.; Conrad, Z.J.; Cao, J.N.; Zhang, X.P. Hovering efficiency optimization of the ducted propeller with weight penalty taken into account. Aerosp. Sci. Technol. 2021, 117, 106937. [CrossRef]

31. Li, X.; Dong, Z.-Q.; Yu, P.; Wang, L.-P.; Niu, X.-D.; Yamaguchi, H.; Li, D.-C. Effect of self-assembly on fluorescence in magnetic multiphase flows and its application on the novel detection for COVID-19. Phys. Fluids 2021, 33, 042004. [CrossRef]

32. Jiang, C.; Xiang, L.; Miao, S.; Shi, L.; Xie, D.; Yan, J.; Zheng, Z.; Zhang, X.; Tang, Y. Flexible Interface Design for Stress Regulation of a Silicon Anode toward Highly Stable Dual-Ion Batteries. Adv. Mater. 2020, 32, 1908470. [CrossRef]

33. Lu, Z.-Q.; Zhao, L.; Ding, H.; Chen, L.-Q. A dual-functional metamaterial for integrated vibration isolation and energy harvesting. J. Sound Vib. 2021, 509, 116251. [CrossRef]

34. Pordanjani, A.H.; Aghakhani, S.; Afrand, M.; Sharifpur, M.; Meyer, J.P.; Xu, H.; Ali, H.M.; Karimi, N.; Cheraghian, G. Nanofluids: Physical phenomena, applications in thermal systems and the environment effects-A critical review. J. Clean. Prod. 2021, 320, 128573. [CrossRef]

35. Dutta, S.; Biswas, A.K.; Pati, S. Natural convection heat transfer and entropy generation inside porous quadrantal enclosure with nonisothermal heating at the bottom wall. Numer. Heat Transf. Part A Appl. 2018, 73, 222-240. [CrossRef]

36. Kefayati, G.R.; Tang, H. Double-diffusive laminar natural convection and entropy generation of Carreau fluid in a heated enclosure with an inner circular cold cylinder (Part II: Entropy generation). Int. J. Heat Mass Transf. 2018, 120, 683-713. [CrossRef]

37. Sadeghi, M.S.; Dogonchi, A.S.; Ghodrat, M.; Chamkha, A.J.; Alhumade, H.; Karimi, N. Natural convection of CuO-water nanofluid in a conventional oil/water separator cavity: Application to combined-cycle power plants. J. Taiwan Inst. Chem. Eng. 2021, 124, 307-319. [CrossRef] 
38. Shaw, S.; Nayak, M.K.; Dogonchi, A.S.; Chamkha, A.J.; Elmasry, Y.; Alsulami, R. Hydrothermal and entropy generation analyses of magneto-cross nanoliquid under rectified Fourier viewpoint: A robust approach to industrial applications. Case Stud. Therm. Eng. 2021, 26, 100974. [CrossRef]

39. Salari, M.; Rezvani, A.; Mohammadtabar, A.; Mohammadtabar, M. Numerical Study of Entropy Generation for Natural Convection in Rectangular Cavity with Circular Corners. Heat Transf. Eng. 2015, 36, 186-199. [CrossRef]

40. Sheikholeslami, M.; Ganji, D.D. Entropy generation of nanofluid in presence of magnetic field using Lattice Boltzmann Method. Phys. A Stat. Mech. Its Appl. 2015, 417, 273-286. [CrossRef]

41. Shojaeian, M.; Koşar, A. Convective heat transfer and entropy generation analysis on Newtonian and non-Newtonian fluid flows between parallel-plates under slip boundary conditions. Int. J. Heat Mass Transf. 2014, 70, 664-673. [CrossRef]

42. Mahian, O.; Mahmud, S.; Wongwises, S. Entropy generation between two rotating cylinders with magnetohydrodynamic flow using nanofluids. Thermophys. Heat Transf. 2013, 27, 161-169. [CrossRef]

43. Pordanjani, A.H.; Aghakhani, S. Numerical Investigation of Natural Convection and Irreversibilities between Two Inclined Concentric Cylinders in Presence of Uniform Magnetic Field and Radiation. Heat Transf. Eng. 2021, 1-21. [CrossRef]

44. Aghakhani, S.; Pordanjani, A.H.; Afrand, M.; Sharifpur, M.; Meyer, J.P. Natural convective heat transfer and entropy generation of alumina/water nanofluid in a tilted enclosure with an elliptic constant temperature: Applying magnetic field and radiation effects. Int. J. Mech. Sci. 2020, 174, 105470. [CrossRef]

45. Khodadadi, H.; Aghakhani, S.; Majd, H.; Kalbasi, R.; Wongwises, S.; Afrand, M. A comprehensive review on rheological behavior of mono and hybrid nanofluids: Effective parameters and predictive correlations. Int. J. Heat Mass Transf. 2018, 127, 997-1012. [CrossRef]

46. Pak, B.C.; Cho, Y.I. Hydrodynamic and heat transfer study of dispersed fluids with submicron metallic oxide particles. Exp. Heat Transf. 1998, 11, 151-170. [CrossRef]

47. Bhanvase, B.A.; Sarode, M.R.; Putterwar, L.A.; Abdullah, A.K.; Deosarkar, M.P.; Sonawane, S.H. Intensification of convective heat transfer in water/ethylene glycol based nanofluids containing $\mathrm{TiO}_{2}$ nanoparticles. Chem. Eng. Process. Process. Intensif. 2014, 82, 123-131. [CrossRef]

48. Sarafraz, M.M.; Hormozi, F. Intensification of forced convection heat transfer using biological nanofluid in a double-pipe heat exchanger. Exp. Therm. Fluid Sci. 2015, 66, 279-289. [CrossRef]

49. Natsuki, J.; Natsuki, T.; Hashimoto, Y. A review of silver nanoparticles: Synthesis methods, properties and applications. Int. J. Mater. Sci. Appl. 2015, 4, 325-332. [CrossRef]

50. Natsuki, T.; Natsuki, J. One-step synthesis of silver nanoparticles using low molecular weight compounds at room temperature. Int. J. Mater. Eng. Technol. 2015, 13, 109. [CrossRef]

51. Żyła, G.; Fal, J. Viscosity, thermal and electrical conductivity of silicon dioxide-ethylene glycol transparent nanofluids: An experimental studies. Thermochim. Acta 2017, 650, 106-117. [CrossRef]

52. Cheraghian, G. Improved heavy oil recovery by nanofluid surfactant flooding-an experimental study. In Proceedings of the 78th EAGE Conference and Exhibition 2016, Vienna, Austria, 30 May-2 June 2016. [CrossRef]

53. Cheraghian, G.; Nezhad, S.S.K.; Bazgir, S. Improvement of thermal stability of polyacryl amide solution used as a nano-fluid in enhanced oil recovery process by nanoclay. Int. J. Nanosci. Nanotechnol. 2015, 11, 201-208.

54. Pirmohammadi, M.; Ghassemi, M. Effect of magnetic field on convection heat transfer inside a tilted square enclosure. Int. Commun. Heat Mass Transf. 2009, 36, 776-780. [CrossRef] 